Portland State University

PDXScholar

6-5-1969

\title{
Cyclization Studies Involving the Synthesis of 5-Substituted-1-Naphthol
}

Clark Keelock Chow

Portland State University

Follow this and additional works at: https://pdxscholar.library.pdx.edu/open_access_etds

Part of the Chemistry Commons

Let us know how access to this document benefits you.

Recommended Citation

Chow, Clark Keelock, "Cyclization Studies Involving the Synthesis of 5-Substituted-1-Naphthol" (1969).

Dissertations and Theses. Paper 424.

https://doi.org/10.15760/etd.424

This Thesis is brought to you for free and open access. It has been accepted for inclusion in Dissertations and Theses by an authorized administrator of PDXScholar. Please contact us if we can make this document more accessible: pdxscholar@pdx.edu. 
AN ABSTRACT OF THE THESIS OF

Clark Keelock Chow

(Name) for the

M.S.

(Degree) in Chemistry

(Major)

Date thesis is presented: June 5, 1969

Title: Cyclization Studies Involving the Synthesis of 5-Substituted1-naphtho1.

Abstract approved:

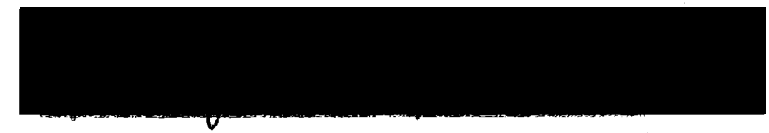

(Major Professor)

The $\gamma$-o-substituted-phenylparaconic acids were prepared by a method patterned after that of Fuson. These paraconic acids were prepared in good yield. A re-investigation of the Perkin and Fittig methods of preparing $\gamma$-phenylisocrotonic acid was carried out without success.

The synthesis of $\gamma$-o-h-halophenylisocrotonic acids by thermal, and catalyzed decarboxylation of $\gamma$-o-halophenylparaconic acid, have been carried out in good yield. An effective catalyst, optimum temperature and reaction period of decarboxylation of the $\gamma$-o-halopheny1paraconic acids have been determined. Infrared absorptions have characterized the $\gamma$-o-halophenylisocrotonic acids formed to be in the stable trans form.

Cyclization of $\gamma$-o-halophenylisocrotonic acids was accomplished by isomerization of the trans acid to cis acid by ultra-violet irra- 
diation, followed by refluxing in the presence of sodium acetate and acetic anhydride. The subsequent hydrolysis of the acetylatednaphthol afforded the 5-ha10-1-naphthol. 
CYCLIZATION STUDIES INVOLVING THE

SYNTHESIS OF 5-SUBSTITUTED-1-NAPHTHOL

by

CLARK KEELOCK CHOW

\begin{abstract}
A thesis submitted in partial fulfillment of the requirements for the degree of
\end{abstract}

MASTER OF SCIENCE

in

CHEMISTRY

Portland State University

1969 
TO THE OFFICE OF GRADUATE STUDIES:

The members of the Committee approve the thesis of Clark Reelock Chow, presented Jund 5, 1969.

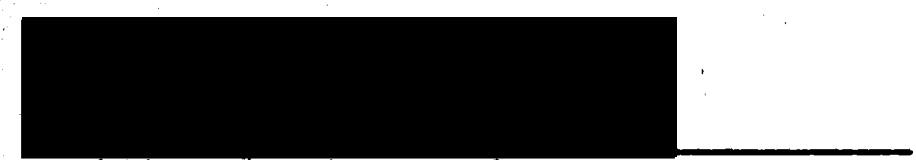

PhIlip C. Robert1, Chairman

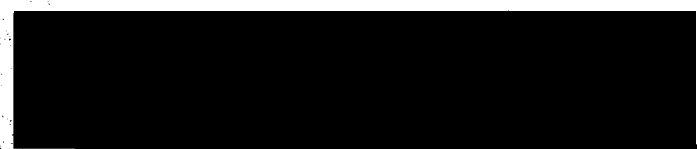

M. Bernard Silverman

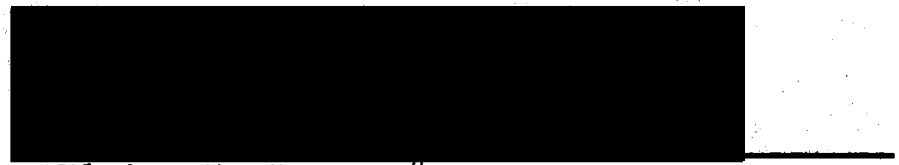

Elaine E. Spencey]

APPROVED:

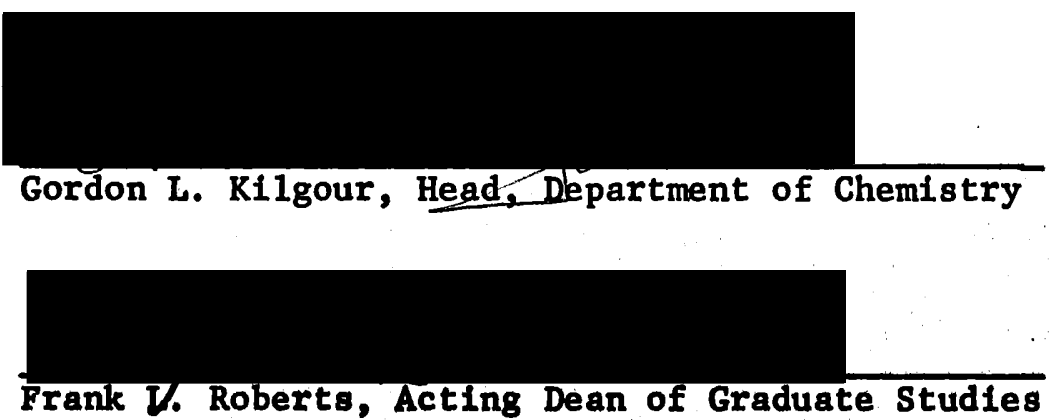

June 5,1969 
TABLE OF CONTENTS

Page

Acknowledgement . . . . . . . . . . . . . .

List of Tables . . . . . . . . . . . . . .

Chapter

I. Introduction ..................

II. Historical ..................

Preparation of $\gamma-\underline{o}$; or $\mathrm{p}$-substituted-phenylparaconic Acids and $\gamma-\underline{o}$, or p-substituted-pheny1isocrotonic Acids. . . ...........

Preparation of 5- and 7-halo-1-naphthols .....

III. Discussion .................

Preparation of Paraconic Acids . . . . . . . . Decarboxylation of $\gamma$-o-substituted-phenylparaconic Acid .....................

Cyclization . . . . . . . . . . . . .

IV. Experimental ...............

o-Bromobenzaldehyde Diacetate . . . . . . . 23

o-Bromobenzaldehyde . . . . . . . . . . . . ' 23

o-Iodotoluene . . . . . . . . . . . . . . . 24

o-Iodobenzaldehyde ............... . . . 25

$\bar{\gamma}$-o-Ch1orophenylparaconic Acid . . . . . . ... 26

$\gamma$-o-Bromophenylparaconic Acid . . . . . . . 27

$\gamma$-o-Fluorophenylparaconic Acid . . . . . . . . 27

$\gamma$-o-Todophenylparaconic Acid . . . . . . . . . 28

$\gamma$-o-Nitrophenylparaconic Acid .......... 28

Determination of the Molecular Weight of $\gamma$-o-Halophenylparaconic Acid ............... 29

Decarboxylation of $\gamma$-o-Chlorophenylparaconic Acid . 29

Decarboxylation of $\gamma$-o-Bromophenylparaconic Acid . . 30

Decarboxylation of $\gamma-\bar{o}-$ Fluorophenylparaconic Acid . $\quad 31$

Decarboxylation of $\gamma$-o-Iodophenylparaconic Acid . • 31

Determination of Molecular Weight of $\gamma$-o-Halopheny1isocrotonic Acid . . . . . . . . . . . .

Cyclization of $\gamma$-o-Chlorophenylisocrotonic Acid . . Cyclization of $\gamma-\underline{0}-$ Bromophenylisocrotonic Acid ... . 
Table of Contents (cont.)

Page

v. Summary ................ . . 35

VI. Bibliography ............... 36 


\section{ACKNOWLEDGMENT}

The author wishes to express his deepest gratitude to his grandfather, Chow Chung Ting, for his encouragement which has contributed greatly to the success of this work.

The author wishes to express his sincere gratitude to Dr. Philip C. Roberti for his understanding and faithful guidance during the research project; Dr. Morris B. Silverman for his encouragement and Dr. John R. Mickelsen and Dr. Raymond P. Lutz for their helpful suggestions and comments. Also, the author wishes to thank Greg Rousett for preparing needed reagents.

This Thesis is dedicated to my Grandmother

Chan Su-Ying 
LIST OF TABLES

TABLE

Decarboxylation of $\gamma$-o-Chlorophenylparaconic Acid .................

Therma1 Decarboxylation of $\gamma$-o- -Chloropheny1paraconic Acid . . . . . . . . . . .

Acid-Catalyzed Decarboxylation of $\gamma$-o-Ch1orophenylparaconic Acid . . . . . . . . .

Acid-Catalyzed Decarboxylation of $\gamma$-o-Bromophenylparaconic Acid . . . . . . . . •

Acid-Catalyzed Decarboxylation of $\gamma$-o-Fluorophenylparaconic Acid . . . . . . . . .

Acid-Catalyzed Decarboxylation of $\boldsymbol{\gamma}$-o-Iodophenylparaconic Acid . . . . . . . . .

IX

Molecular Weight Determination of $\gamma$-o- - Halophenylparaconic Acid ........... 


\section{INTRODUCTION}

The purpose of this research was to carry out the synthesis of 5-substituted-1-naphthols via a method involving cyclization of the intermediate, $\gamma$-o-substituted-phenylisocrotonic acid. In particular it was necessary that 5-nitro-1-naphthol be prepared since this compound was required in the further study of the oxidative ring cleavage of substituted-nitronaphthalenes.

Some of these substituted-naphthols have been prepared by other methods which are time consuming, tedious, or inadequate in terms of yields.

The synthesis of the substituted naphthols involved three steps which are shown in the following schematic series:<smiles>[X]c1ccccc1C=O</smiles><smiles>O=C1C[C@@H]2C[C@@H]1C(=O)O2</smiles><smiles>[X]c1ccccc1C1OC(=O)CC1C(=O)O</smiles>

(I)

(I)

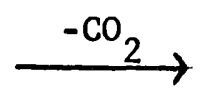<smiles>[X]c1ccccc1/C=C/CC(=O)O</smiles>

(II)<smiles></smiles><smiles>[X]c1cccc2c(O)cccc12</smiles>

$$
\mathrm{X}=\mathrm{F}, \mathrm{Cl}, \mathrm{Br}, \mathrm{I}, \mathrm{NO}_{2}
$$


The o-substituted-benzaldehyde was converted to the $\gamma$-o-substituted-phenylparaconic acid which in turn was heated or treated with a catalyst. The latter operation permitted the decarboxylation of the $\gamma$-o-substituted-phenylparaconic acid and the subsequent formation of the $\gamma$-o-substituted-phenylisocrotonic acid. The $\gamma$-o-substitutedphenylisocrotonic acid was cyclized to an acetyl derivative which was easily hydrolyzed to the desired naphthol. 


\section{HISTORICAL}

The historical section will be discussed under the following headings: (a) Preparation of $\gamma_{-}-\underline{\text {, or }} \mathrm{p}$-substituted-phenylparaconic acids and $\gamma$-o, or $p^{-s u b s t i t u t e d-p h e n y 1 i s o c r o t o n i c ~ a c i d s . ~(b) ~ P r e-~}$ paration of 5- and 7-halo-1-naphthols.

Preparation of $\gamma$-o, or $\mathrm{p}$-substituted-phenylparaconic Acids and $\gamma$-o, or p-substituted-pheny 1 isocrotonic Acids.

The synthesis of cinnamic acid and its analogs by the interaction of an aromatic aldehyde with an acid anhydride in the presence of a salt of an acid was first reported by Perkin in 1868 (1).

In 1883, Fittig and Jayne (2) found that if benzaldehyde was allowed to react with succinic anhydride and sodium succinate at $100^{\circ} \mathrm{C}$, the product was $\gamma$-phenylparaconic acid. Furthermore, they observed that on heating $\gamma$-phenylparaconic acid, carbon dioxide was lost and the $\beta, \gamma$-unsaturated acid, $\gamma$-phenylisocrotonic acid was formed.

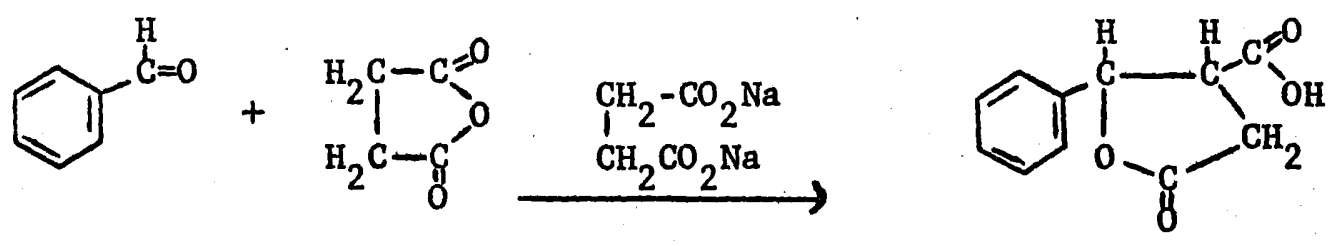

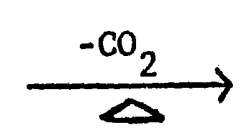<smiles>O=C(O)C=Cc1ccccc1</smiles> 
The latter compound was also reported by Perkin when the above reaction was conducted at $150^{\circ} \mathrm{C}(3,4)$.

The synthesis of $\gamma-\underline{o}$, and $\mathrm{p}$-chlorophenylparaconic acid was reported by Erdmann (5) in 1888 by the condensation of of or p-chlorobenzaldehyde, succinic anhydride and sodium acetate. The distillation of $\gamma$-o or $\mathrm{p}$-chlorophenylparaconic acid yielded $\gamma$-o, or $\mathrm{p}$-chloropheny $1-$ isocrotonic acids, respectively (6).

Patterned after the method of Erdmann (5), Fuson (7) in 1924 was able to prepare the $\gamma$-o-bromophenylparaconic acid in $50 \%$ yield. A year later, Fuson (8) reported the synthesis of $\gamma$-m-bromopheny1paraconic acid in $20 \%$ yle $1 \mathrm{~d}$ as well as the $\gamma-\mathrm{p}$-bromophenylparaconic acid.

The synthesis of $\gamma$-p-nitro-phenylparaconic acid was carried out by A. Angeletti in 1929 (9). The $\gamma$-o-nitrophenylisocrotonic acid was reported in 1934 by F. Schenck (10). The synthesis of the latter involved the condensation of $\alpha$-(o-nitropheny 1$)$ acetaldehyde and malonic acid.

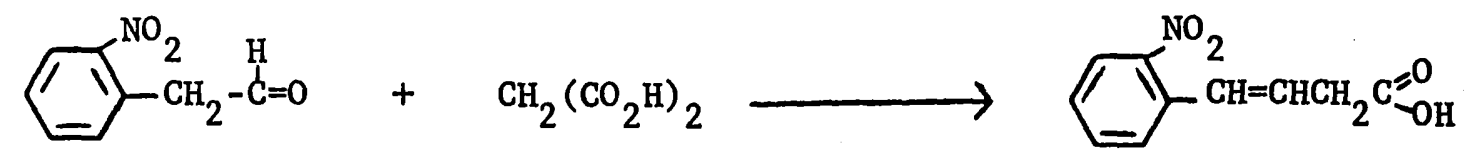

A modification of the Reformatsky Reaction by Miller and Nord (11) in 1951, enabled these investigators to prepare the $\gamma$-pheny 1 isocrotonic acid in $34 \%$ yield. 


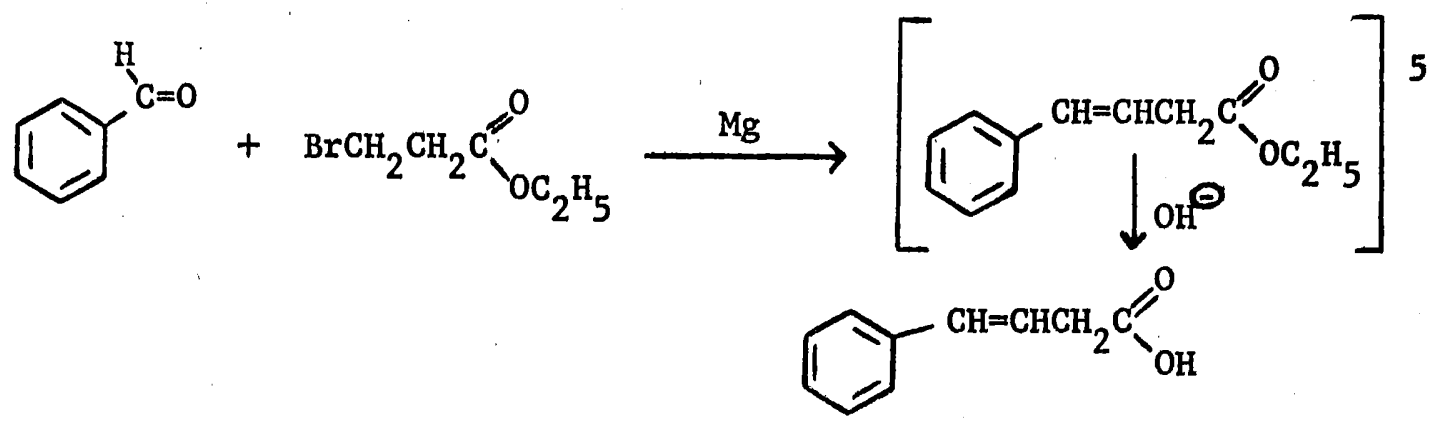

An excellent paper on the re-investigation of the reaction of the sodium succinate with some aromatic aldehydes was published in 1960, by G. M. Anteunis (12). A new technique was described by this investigator which increased the yield of the $\gamma$-phenylparaconic acid to $85 \%$. He also found that it was better to prepare $\gamma$-pheny 1 paraconic acid first, and then convert it into $\gamma$-phenylisocrotonic acid in a separate step, rather than to carry out the preparation of the $\gamma$-phenylisocrotonic acid directly by allowing sodium succinate and benzaldehyde to react at a higher temperature.

In 1964, Oda, Kawabata, and Tanimoto (13) were able to obtain $\gamma-p$-chlorophenylisocrotonic acid in $55 \%$ yield via the reaction of $\mathrm{p}$-chlorobenzaldehyde, and the ylide (14), $\emptyset_{3} \mathrm{P}=\mathrm{CHCH}_{2} \mathrm{C}-\mathrm{OEt}$.<smiles></smiles>

Preparation of 5- and 7-halo-1-naphthols.

The earliest report of the synthesis of 5- or 7-halo-1-naphtho1 was by Erdmann and Kirchhoff (15) in 1888. They demonstrated that on heating $\underline{\mathrm{o}}-$, or $\mathrm{p}$-chlorophenylparaconic acid rapidly to a higher temperature, 5- or 7-ch1oro-1-naphthol was prepared.

In 1949, Louis Fieser (16) prepared p-chlorophenylparaconic 
acid according to the method of Erdmann, et. al. Distillation of the crude product resulted in a $22 \%$ yield of 7-chloro-1-naphthol.

A rather interesting method was employed by Beech and Legg (17) in the synthesis of 7-chloro-1-naphthol. They were able to convert 8-nitro-2-aminonaphthalene to 7-chloro-1-nitronaphthalene via the Sandmeyer Reaction and then to the naphthol compound by reduction of the nitro compound, followed by diazotization of the aminonaphthalene.

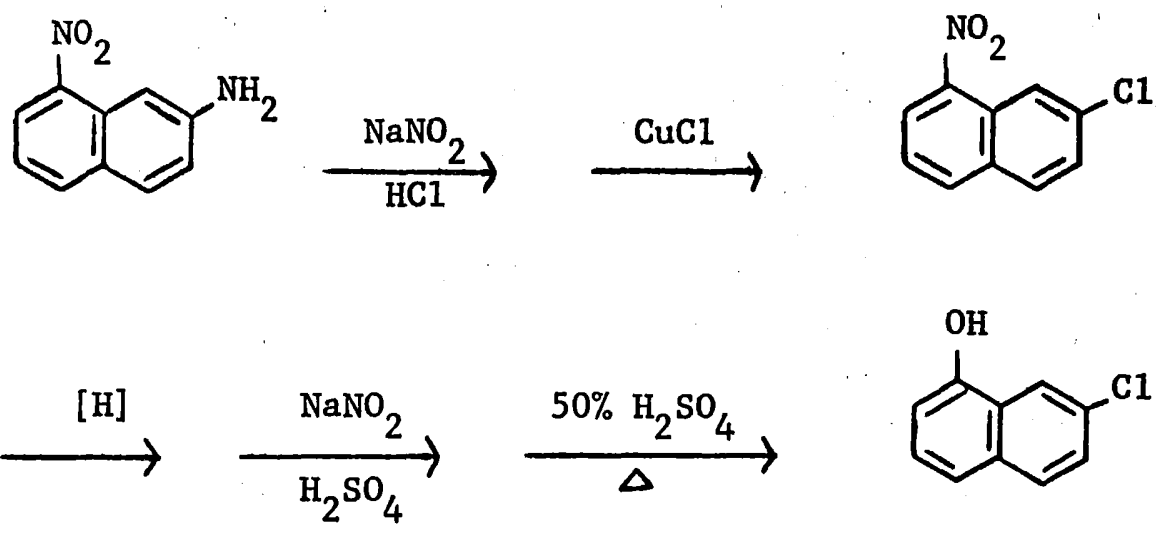

A. P. Luric, et al (18) described the synthesis of 5-chloro-1naphthol from 5-amino-1-naphthol using the Sandmeyer Reaction. The yield of the desired naphthol was about $8 \%$.<smiles>Nc1cccc2c(O)cccc12</smiles>

In 1959, Franzen (19) demonstrated that 7-chloro-1-naphtho1 could be prepared by the cyclization of a $\gamma$-p-chlorophenylbutyric acid to the 7-halo-1-tetralone, followed by bromination and dehydrobromination of the intermediate. 
<smiles>O=C(O)CCc1ccc(Cl)cc1</smiles><smiles>CC</smiles><smiles>CC1CCC(=O)c2cc(Cl)ccc2C1</smiles>

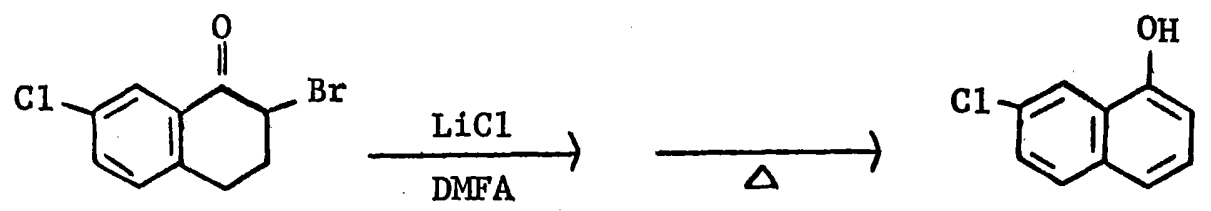

Vorozhtov and Lisitsyn (20) in 1960, published a report which indicated that 5-ch1oro-1-naphthol was obtained in $82 \%$ yield by heating 1,5, dichloronaphthalene with powdered sodium hydroxide and copper powder in methanol.<smiles>Clc1cccc2c(Cl)cccc12</smiles><smiles>CC(C)(O)CCC(C)(O)O</smiles><smiles>Oc1cccc2c(Cl)cccc12</smiles>

In 1961, E1-Abbady, et a1 (21) described the preparation of 5-chloro-1-naphthol via the Stobbe condensation. It involved the reaction of $\underline{o}-$ chlorobenzaldehyde and methylsuccinate in $\underline{t}$-buty 1 alcohol and potassium $\underline{t}$-butoxide to give methyl hydrogen $\underline{\text { cis }}$ $\gamma$-o-chlorophenylitaconate. The latter compound was then treated with sodium acetate and acetic anhydride to give methyl 4-acetoxy8-chloro-2-naphthoate (22). Subsequent hydrolysis, methylation, decarboxylation, and demethylation afforded 5-chloro-1-naphthol (23). The 7-chloro-1-naphthol was also made starting, with the $\mathrm{p}$-chlorobenzaldehyde. 


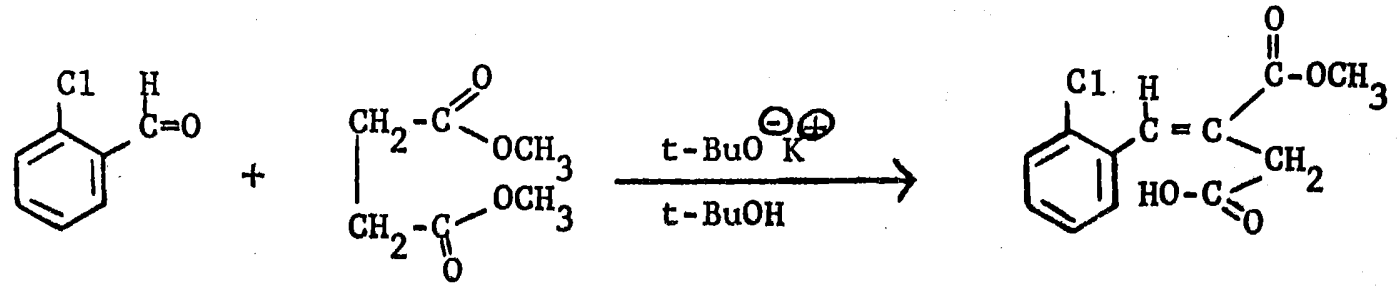<smiles>COC(=O)Oc1cc(C(=O)OC)cc2c(Cl)cccc12</smiles><smiles>COc1cc(C(=O)O)cc2c(Cl)cccc12</smiles>

The compound, 5-bromo-1-naphthol was prepared by Fuson (7) in 1924 by the method of Erdmann, which involved the heating of $\gamma$-obromophenylparaconic acid rapidly to a high temperature. He also announced the preparation of the same naphthol by a different procedure as illustrated below $(24,25)$ :

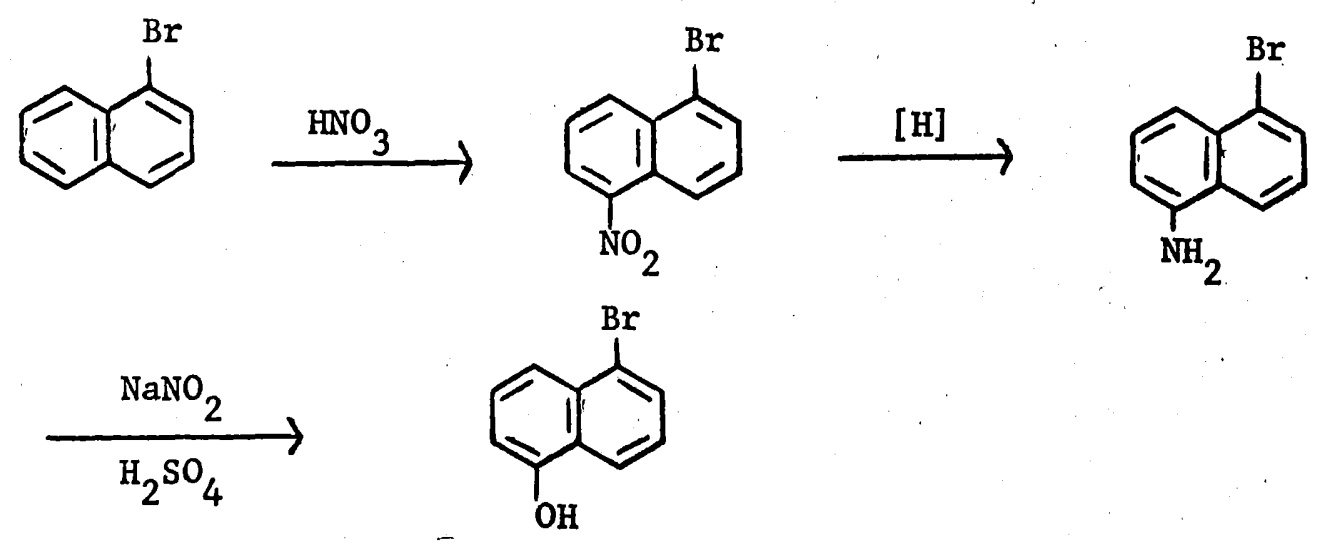


Hill and Short (26) also described a method for the preparation of 5-bromo-1-naphthol involving the bromination of 1-nitronaphthalene, reduction of the nitro compound to 5-bromo-1-aminonaphthalene, diazotization of the amino compound and thence to the product in $41 \%$ yield. An elegant paper on the synthesis of $\alpha$, or $\beta$-fluoronaphthalene derivatives is that of Adcock and Dewar (27). These investigators reported that 7-fluoro-1-naphthol could be prepared by the following route $(28,29)$ :<smiles>Fc1ccccc1</smiles><smiles>O=C1O[C@H]2C[C@H]1CC2=O</smiles><smiles>Cl[Mg]C1CCC1</smiles><smiles>O=C(O)CCC(=O)c1ccc(F)cc1</smiles>

(1) $\mathrm{SOCl}_{2}$

(2) $\mathrm{AlCl}_{3}$<smiles>[3H]c1ccc2c(c1)C(=O)CCC2</smiles><smiles>C[14C]1CCC1(C)C</smiles><smiles>[3H]c1ccc2cccc(O)c2c1</smiles>

The 5-iodo-1-naphthol was synthesized by Scho11 and Seer (30), in 1922, according to the following schematic series:<smiles>[Y]c1cccc2c([N+](=O)[O-])cccc12</smiles> 
III. DISCUSSION

The data is discussed in three sections as a matter of convenience. The first section is considered under the general heading, Preparation of paraconic acids; the second, Decarboxylation; and the third, Cyclization.

Preparation of paraconic acids.

It had been reported by Fittig and Jayne that $\gamma$-phenylisocrotonic acid could be prepared exclusively if benzaldehyde and succinic anhydride were allowed to react at $170^{\circ} \mathrm{C}$. Therefore, it was decided initially to carry out the condensation of o-chlorobenzaldehyde and succinic anhydride at the higher temperature with the intention of isolating $\gamma$-o-chlorophenylisocrotonic acid directly. Instead of the expected product, only a tarry material was obtained, from which no $\gamma$-o-chlorophenylisocrotonic acid could be isolated. In another run, this time with o-bromobenzaldehyde, the results again were negative. It therefore became necessary to prepare the $\gamma$-o-substituted-pheny1paraconic acid first and then convert it in a separate step into the $\gamma$-o-substituted-phenylisocrotinic acid as had been suggested by Anteunis (12).

The synthesis of $\gamma$-o-substituted-phenylparaconic acid was accomplished as illustrated in the following schematic series:<smiles>C[13C](=O)[O-]</smiles> 

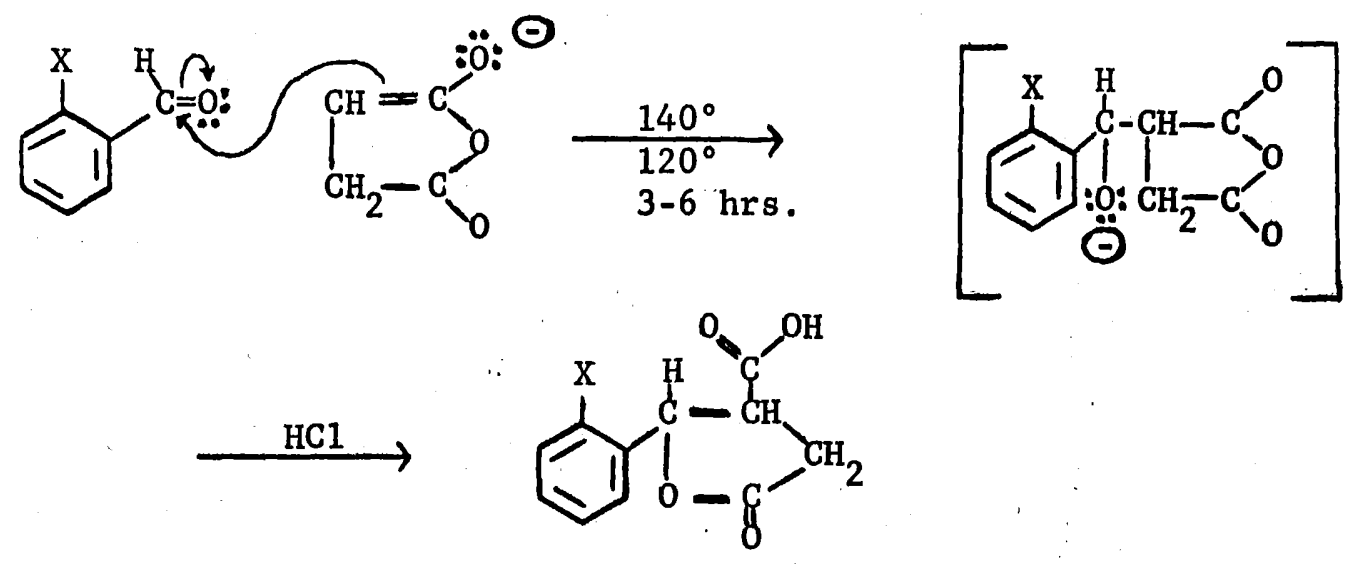

$$
\mathrm{X}=\mathrm{F}, \mathrm{Cl}, \mathrm{Br}, \mathrm{I}, \mathrm{NO}_{2}
$$

The procedure followed was essentially that of C. Fuson (7) with slight modification. The data is shown in Table I.

\section{TABLE I}

\begin{tabular}{|c|c|c|c|}
\hline Product & Temperature & Time & Yield \\
\hline $\begin{array}{l}\gamma \text {-o-Fluoropheny } 1- \\
\text { paraconic acid }\end{array}$ & $140^{\circ}, 120^{\circ}$ & $\begin{array}{l}3 \mathrm{hrs.} \\
6 \mathrm{hrs} \text {. }\end{array}$ & $\begin{array}{l}62.0 \% \\
41.0 \%\end{array}$ \\
\hline $\begin{array}{l}\gamma-0-\text { Chlorophenyl- } \\
\text { paraconic acid }\end{array}$ & $140^{\circ}, 120^{\circ}$ & 3 hrs. & $81.2 \%$ \\
\hline $\begin{array}{l}\gamma \text {-o-Bromophenyl- } \\
\text { paraconic acid }\end{array}$ & $140^{\circ}, 120^{\circ}$ & $\begin{array}{l}5 \text { hrs. } \\
3 \text { hrs. }\end{array}$ & $\begin{array}{l}64.2 \% \\
75.3 \%\end{array}$ \\
\hline $\begin{array}{l}\gamma \text {-o-Iodopheny } 1- \\
\text { paraconic acid }\end{array}$ & $140^{\circ}, 120^{\circ}$ & 5 hrs. & $74.4 \%$ \\
\hline $\begin{array}{l}\gamma \text {-o-Nitrophenyl- } \\
\text { paraconic acid }\end{array}$ & $140^{\circ}, 120^{\circ}$ & 3 hrs. & $38.3 \%$ \\
\hline
\end{tabular}

The reaction between $\underline{0}-f 1$ uorobenzaldehyde or o-nitrobenzaldehyde and succinic anhydride took place quite rapidly at $140^{\circ} \mathrm{C}$. However, this was not the case with the o-chlorobenzaldehyde, o-bromobenzaldehyde, or o-iodobenzaldehyde. Nevertheless, analogous results were obtained in all paraconic acids synthesis. 
In the preparation of each paraconic acid, an intractable tar. was obtained as a by-product. No attempt was made to 1solate or identify any product from the resinous material.

As the reaction time was reduced from either six or five hours to three hours in the synthesis of $\gamma$-o-fluoro or $\gamma$-o-bromopheny1paraconic acid, the yield was increased. In the case of the $\gamma$-o-nitrophenylparaconic acid, the yield was rather mediocre even at the three hour period. No additional experiments were conducted to determine if the reaction time could be shortened to improve the yield.

One may interpret the difference in yields between the $\gamma_{-0}-$ halophenylparaconic acid, and $\gamma$-o-nitrophenylparaconic acid as due to steric effects (31). The steric effects decrease in the order $\mathrm{NO}_{2}, \mathrm{I}$, $\mathrm{Br}, \mathrm{Cl}$, and $\mathrm{F}$. Therefore, the nitro substituent would offer the most steric strain or steric hindrance which may account for the lower yield.

Decarboxylation of $\gamma$-o-substituted-phenylparaconic acid.

Paraconic acids are known to be susceptible to decarboxylation (32). Fittig (33) had reported the thermal decarboxylation of phenylparaconic acid produced $\gamma$-phenylbutyrolactone, $\gamma$-phenylisocrotonic acid and also a small amount of allylbenzene. When $\gamma$-o-chlorophenylparaconic acid was subjected to a thermal decarboxylation at $150^{\circ}$ for half an hour, no observable reaction occured. When $\gamma$-o-chlorophenylparaconic acid was heated at a higher temperature, $205^{\circ} \pm 5^{\circ}$, for a period of two and one-half hours under a nitrogen atmosphere, a $6 \%$ yield of $\gamma$-o-chlorophenylisocrotonic acid was obtained along with 
$42 \%$ recovery of the starting material. Distillation of $\gamma$-o-chlorophenylparaconic acid under nitrogen atmosphere at $270-280^{\circ}$ caused extensive carbonization; $\gamma$-o-ohlorophenylisocrotonic acid was not isolated.

Attempted decarboxylation of $\gamma$-o-chlorophenylparaconic acid employing either copper powder alone or copper powder in quinoline did not give an effective reaction; only a trace of $\gamma$-o-chloropheny1isocrotonic acid was detected.

\section{TABLE II}

Decarboxylation of $\gamma$-o-Chlorophenylparaconic Acid $\gamma$-o-Chloropheny1Temperature Time Catalyst Condition 1socrotonic acid Residue

\begin{tabular}{|c|c|c|c|c|c|}
\hline $150^{\circ}$ & $30 \mathrm{~min}$. & -- & -- & -- & $\begin{array}{l}\text { Starting } \\
\text { material }\end{array}$ \\
\hline $186 \pm 3^{\circ}$ & $180 \mathrm{~min}$ & --- & -- & $4 \%$ & $\begin{array}{c}57 \% \\
\text { Starting } \\
\text { material }\end{array}$ \\
\hline $205 \pm 5^{\circ}$ & 150 min. & --- & $\mathrm{N}_{2}$ & $5 \%$ & $\begin{array}{c}42 \% \\
\text { Starting } \\
\text { material }\end{array}$ \\
\hline $235 \pm 5^{\circ}$ & 150 min. & $\mathrm{Cu}$ & $\mathrm{N}_{2}$ & -- & $?$ \\
\hline $230^{\circ}$ & $180 \mathrm{~min}$. & $\mathrm{Cu}$ & $\mathrm{N}_{2}$ & trace & $?$ \\
\hline $70-280^{\circ}$ & 40 min. & $=-$ & $\mathrm{N}_{2}$ & $\ldots$ & $?$ \\
\hline
\end{tabular}

Refluxing $\gamma$-o-chlorophenylparaconic acid in a high bolling solvent $2,2^{\prime}$ oxydiethanol (B.P. $245^{\circ}$ ) caused decarboxylation with the resulting formation of $\gamma$-o-ohlorophenylbutyrolactone. $\gamma$-Lactone was formed via lactonization of $\beta, \gamma$-unsaturated acid through action of mineral acid or heat (34). The equilibrium between the $\beta, \gamma$-un- 
saturated acid and $\gamma$-lactone has been termed by Linstead a "lactoenoic tautomerism" (35). In 1959, Johnson and Petersen (36), reported the formation of an $\beta, \gamma$-unsaturated acid and $\gamma$-lactone via decarboxylation of itaconic acid. They found that the lactone was in a greater concentration before equilibrium was reached. This observation suggested that the lactone was the primary product of the decarboxylation step, and the unsaturated acid was formed via the lacto-enoic tautomerism.

$\gamma$-o-Chlorophenylparaconic acid was decarboxylated at $210^{\circ}$; subsequent hydrolysis of the proposed intermediate $\gamma$-o-chlorophenylbutyrolactone, and dehydration by sulfuric acid resulted only in $\gamma$-o-chlorophenylbutyrolactone instead of the $\gamma$-o-chlorophenylisocrotonic acid.

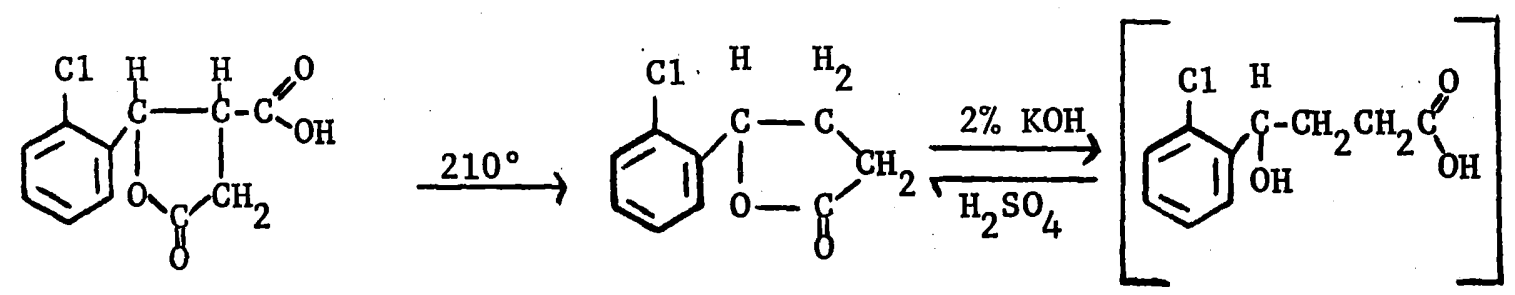

The above observation was contrary to the early premise by Johnson and Petersen (36); however, it is in complete agreement with the latter work of Johnson and Hunt (37).

The formation of $\gamma$-lactone is dependent upon the extent of heat treatment. Upon rapid distillation, the unsaturated acid is formed in higher yield. The unsaturated acid derivative of $\gamma, \gamma$-disubstituted-paraconic acid readily undergoes lactonization upon heating at the boiling point, while the unsaturated acid derivative of $\gamma$-monosubstituted-paraconic acid can be distilled without isomerisation to the 
lactones (38). $\gamma$-Lactone are not generally isomerized to the unsaturated acid $(34,35)$. When $\gamma$-o-chlorophenylisocrotonic acid was treated at room temperature with concentrated sulfuric acid for twenty minutes, $\gamma$-o-chlorophenylbutyrolactone was not found in the reaction mixture.

However; when $\gamma$-o-chlorophenylisocrotonic acid and $\gamma$-o-bromophenylisocrotonic acid were refluxed with dilute sulfuric acid for 2 hours, the $\gamma$-o-bromophenylbutyrolactone was obtained in $35 \%$ yield, and only a trace amount of $\gamma$-o-chlorophenylbutyrolactone was isolated. $\gamma, \gamma$-diphenylisocrotonic acid was isomerized to $\gamma, \gamma$-dipheny1butyrolactone in the presence of cold concentrated sulfuric acid at room temperature within fifteen minutes. This observation is in accordance with the fact that the $\gamma$-substituted $\beta, \gamma$-unsaturated acid does not isomerize to $\gamma$-lactone as easily as the $\gamma, \gamma$-disubstituted $\beta, \gamma$-unsaturated acid. The inert behavior of the $\gamma$-o-halophenylisocrotonic acid towards lactonization suggested that the inductomeric effect and electromeric effect probably stabilizes the $\beta, \gamma$-unsaturated acid.

TABLE III

Thermal Decarboxylation of $\gamma$-o-Chlorophenylparaconic Acid

Temperature

Time $\quad \begin{aligned} & \gamma \text {-o-Chlorophenyl- } \\ & \text { isocrotonic acid }\end{aligned}$
5-Ch1oronaphtho1

$\begin{array}{llll}220^{\circ} & 168 \mathrm{~min} . & 67 \% & \cdots \\ 230^{\circ} & 130 \mathrm{~min} . & 68.02 \% & 4.09 \% \\ 240^{\circ} & 122 \mathrm{~min} . & 63.8 \% & 8.7 \%\end{array}$


TABLE IV

Acid-catalyzed Decarboxylation of $\gamma$-o-Chlorophenylparaconic Acid by $\mathrm{KHSO}_{4}$

\begin{tabular}{|c|c|c|c|}
\hline Temperature & Time & $\begin{array}{l}\gamma \text {-o-Chlorophenyl- } \\
\text { isocrotonic ac1d }\end{array}$ & $\begin{array}{l}\text { 5-Ch1oro- } \\
\text { naphthol }\end{array}$ \\
\hline $220^{\circ}$ & $86 \mathrm{~min}$. & $70.8 \%$ & $6.9 \%$ \\
\hline $230^{\circ}$ & $71 \mathrm{~min}$. & $71.0 \%$ & $8.1 \%$ \\
\hline $240^{\circ}$ & 70 min. & $69.8 \%$ & $8.1 \%$ \\
\hline $250^{\circ}$ & $64 \min$ & $68.9 \%$ & $7.04 \%$ \\
\hline $260^{\circ}$ & 74 min. & $53.0 \%$ & $4.5 \%$ \\
\hline $230-310^{\circ}$ * & $21 \mathrm{~min}$ & $11.6 \%$ & $36 \%$ \\
\hline
\end{tabular}

* $\gamma$-o-Ch1orophenylparaconic acid was distilled at reduced pressure with a rapid increase in temperature.

Decarboxylation of $\gamma$-o-ohlorophenylparaconic acid was carried out under, both, thermal and acid-catalyzed thermal conditions at various temperatures as shown in Table III and Table IV. The experimental results demonstrated that an acid catalyzed reaction reduced the decarboxylation time by one-half as compared to the thermal decarboxylation at the same temperature. Decarboxylation by potassium hydrogen sulfate was accompanied by a more vigorous evolution of gas, and provided for purer products. Thermal decarboxylation required a longer reaction period which could conceivably lead to a competing side reaction i.e. decarboxylation of $\beta, \gamma$-unsaturated acid. No attempt was made to identify the presence of o-chloroallylbenzene as reported by Fittig.

Decarboxylation of $\gamma$-o-bromophenylparaconic acid showed analo- 
gous results as the $\gamma$-o-chlorophenylparaconic actd. The lower yield in the first run of Table $V$ can be attributed to some of the $\beta, \gamma-$ unsaturated acid cyclizing to 5-bromo-1-naphthol.

\section{TABLE V}

Acid-catalyzed Decarboxylation of $\gamma$-o-Bromophenylparaconlc Acld by $\mathrm{KHSO}_{4}^{-}$

$\begin{array}{cccc}\text { Temperature } & \text { Time } & \text { Catalyst } & \text { Yield } \\ 230^{\circ} * & 80 \mathrm{~min} & \mathrm{KHSO}_{4} & 47.5 \% \\ 225^{\circ} & 110 \mathrm{~min} . & \mathrm{KHSO}_{4} & 77.5 \% \\ 230^{\circ} & 105 \mathrm{~min} & \mathrm{KHSO}_{4} & 75 \%\end{array}$

* U.V. irradiation was applied $30 \mathrm{~min}$. before vacuum distillation, $14.5 \%$ of 5-bromo-1-naphthol was also obtained.

Acid-catalyzed decarboxylations of $\gamma$-o-fluoro and $\gamma$-o-iodophenylparaconic were favored by shorter reaction periods The reactions occured instantly with a rapid evolution of carbon dioxide. Prolonged heating resulted in decomposition, as indicated by the occurence of iodine vapors, and charring of $\gamma$-o-fluorophenylparaconic acid. 
TABLE VI

Acid-catalyzed Decarboxylation of $\gamma$-0-F1uorophenylparaconic Acid by $\mathrm{KHSO}_{4}$

$\begin{array}{lll}\text { Temperature } & \text { Time } & \text { Yield } \\ 230^{\circ} * & 90 \mathrm{~min} . & 57 \% \\ 230^{\circ} & 68 \mathrm{~min} . & 77 \% \\ 235^{\circ} & 71 \mathrm{~min} . & 66.4 \% \\ 230 \pm 10^{\circ} & 73 \mathrm{~min} . & 66 \% \\ & \\ \text { * The reactant turned dark brown, indi- } \\ \text { cating carbonization occured. }\end{array}$

TABLE VII

Acid-catalyzed Decarboxylation of $\gamma$-o-Iodophenylparaconic Acid by $\mathrm{KHSO}_{4}$

\begin{tabular}{lrc} 
Temperature & Time & Yield \\
\hline $230^{\circ}$ & $75 \mathrm{~min}$. & $58.8 \%$ \\
$230^{\circ} * *$ & $89 \mathrm{~min}$. & $37.7 \%$ \\
$220 \pm 5^{\circ} * *$ & $-\ldots ?$ & $40.8 \%$ \\
$225 \pm 3^{\circ}$ & $65 \mathrm{~min}$. & $74.0 \%$ \\
$* * \begin{array}{l}\gamma \text {-o-Iodophenylparaconic acid began } \\
\text { to decompose, iodine vapor was detected } \\
\text { in the reaction vessel. }\end{array}$
\end{tabular}

When $\gamma$-o-nitrophenylparaconic acid was subjected to decarboxylation conditions, carbonization occured immediately at temperature above its melting point. This was first observed when the melting 


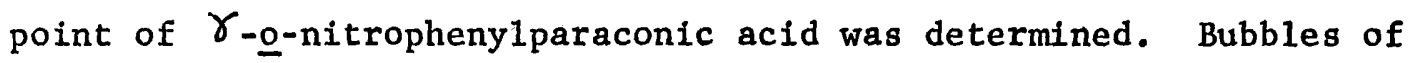
gas occured in the capillary tube and the $\gamma$-o-nitrophenylparaconic acid turned into a dark brown oil. Decarboxylation of $\gamma$-o-nitrophenylparaconic acid was attempted under a nitrogen atmosphere with a catalytic amount of potassium hydrogen sulfate at $210^{\circ}$. The reactant turned to a dark brown oil within five minutes after Immersion in an oil bath at $210^{\circ}$, and vacuum distillation did not yield the expected product.

When $\gamma$-o-nitrophenylparaconic acid was refluxed in petroleum-ether (B.P. $90^{\circ}-120^{\circ}$ ) with a catalytic amount of potassium hydrogen sulfate for 2 hours under a nitrogen atmosphere, no decarboxylation was detected. The addition of a drop of concentrated sulfuric acid caused complete carbonization of the $\gamma$-o-nitrophenylparaconic acid. A possible explanation for the fallure of this reaction could be due to the intensified electronic effect of the o-nitro substituent.

Two schemes for the acid catalyzed decarboxylation of paraconic acids by the potassium hydrogen sulfate have been advanced by Johnson and Hunt (37). The first scheme is referred to as the concerted process as shown in the diagram:

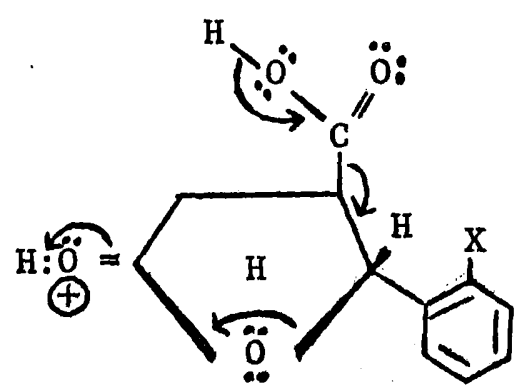


In scheme $I$, protonation of the carbonyl oxygen of the $\gamma$-lactone causes a shift of the electrons and opens the $r$ ing. The electronic effect of the ortho substituent facilitates the shift of the electrons and stabilizes the formation of carbon-carbon double bond by conjugation.<smiles>[X]c1ccccc1C(CC(=O)O)C(CC(=O)O)C(=O)O</smiles>

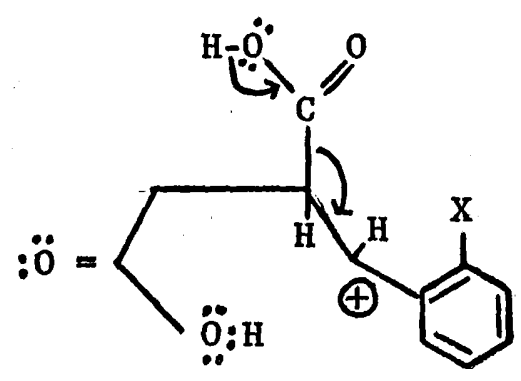

(II)

Scheme II, protonation of ester linkage oxygen results in the rupture of the lactone ring and the formation of benzylic carbonium ion. The latter favours the cleavage of the carbony1 carbon and carbon bond and the formation of $\beta, \gamma$-unsaturated acid.

Scheme III represents thermal decarboxylation of paraconic acid. It is believed that the protonation occurs intramolecularly as shown by the following diagram:

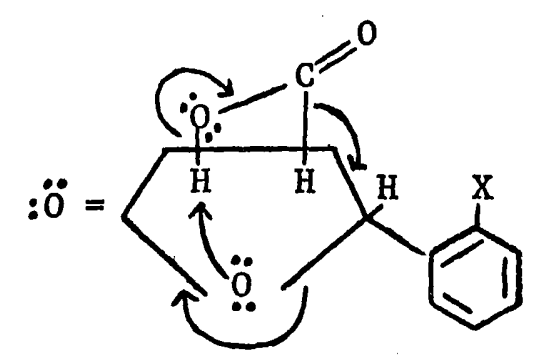

The transfer of a proton is extremely difficult, as shown by the bending of the $\mathrm{C}-\mathrm{O}-\mathrm{H}$ bond. This effect was indicated by the longer reaction time in purely thermal decarboxylation as compared to acidcatalyzed thermal decarboxylation. 


\section{Cyclization}

A classical example of ring closure of $\gamma$-arylcrotonic acid was described by Erdmann. The cyclization of $\gamma$-o-chloropheny1isocrotonic acid was carried out initially in accordance with the method of Erdmann. The reaction involved the direct distillation of $\gamma$-o-bromophenylparaconic acid at an extremely high temperature, $280^{\circ}$ to $320^{\circ}$, which formed the intermediate $\gamma$-o-bromophenylisocrotonic acid and the latter compound underwent cyclodehydration to the desired naphthol derivative. During the reaction extensive carbonization occured; however, a $8 \%$ yield of 5-bromo-1-naphthol was obtained. The preparation of 5-chloro-1-naphthol was carried out by the Fuson's method (7) with some modification. It involved the acidcatalyzed decarboxylation of $\gamma$-o-chlorophenylparaconic acid and the vacuum distillation of the reaction mixture at $230^{\circ}$ to $310^{\circ}$. A $36 \%$ yield of the 5-chloro-1-naphthol was obtained. This modified method afforded higher yields than either the Erdmann ring closure method or method of Fuson.

The cyclization of $\gamma$-o-substituted-phenylisocrotonic acids was patterned after the method of Badder, et a1 $(39,40)$, with some modification. $\gamma$-o-Substituted-pheny $1 \beta, \gamma$-unsaturated acids having the appropriate stereochemical configuration, that is, an aryl group cis to the $-\mathrm{CH}_{2} \mathrm{CO}_{2} \mathrm{H}$ group, can undergo intramolecularly cyclodehydration and enolization to give the substituted naphthols. An attempt to cyclize $\gamma$-o-chlorophenylisocrotonic acid directly by refluxing sodium acetate and acetic anhydride $(39,41,42)$, was not successful. 
Evidently the compound, $\gamma$-o-ohlorophenylisocrotonic acid remained in the stable trans form.

The conversion of the trans acid to the cis isomer was accomplished by photoisomerization. $\gamma$-o-chlorophenylisocrotonic acld was irradiated with a U.V. source for half an hour while refluxing with sodium acetate and acetic anhydride. Hydrolysis of 5-chloro-1-acetoxynaphthalene gave a $62.2 \%$ yield of 5-chloro-1-naphthol. Cyclization of other $\gamma$-o-halo-phenylisocrotonic acids to 5-halo-1-naphthol can be accomplished by the same method.<smiles>[X]c1ccccc1/C=C\CC(=O)O</smiles><smiles>[X]c1ccccc1C=CCC(=O)O</smiles><smiles>[X]c1cccc2c(O)cccc12</smiles>

TABLE VIII

Yield of 5-halo-1-naphthol

$\begin{array}{cccc}\text { F } & \text { C1 } & \text { Br } & \text { I } \\ 46.5 \% & 62.2 \% & 51.1 \% & 40.5 \%\end{array}$

The entire operation - isomerization, cyclization and hydrolysis was carried out in the same reaction vessel; thereby, reducing the isolation problem. 


\section{EXPERIMENTAL}

o-Bromobenza1dehyde Diacetate

This compound was prepared by the method of Tsang and Wood (43). In a three liter, three-necked, round bottom flask equipped with a mechanical stirrer and a thermometer, and surrounded by an ice bath, were placed one liter of glacial acetic acid, one liter of acetic anhydride, and $120 \mathrm{ml}$ of concentrated sulfuric acid. When the solution was cooled to $0^{\circ} \mathrm{C}, 100 \mathrm{~g}(70 \mathrm{ml})$ of o-bromotoluene was added. After the solution reached a temperature of $5^{\circ}, 170 \mathrm{~g}$ of chromium trioxide was added slowly at such a rate that the temperature did not rise above $10^{\circ} \mathrm{C}$; about two hours were required for the addition. Stirring was continued for five hours after the chromium trioxide had been added. The reaction mixture was added to a crock that was one-half full of ice. The residue in the flask was washed out with ice water and the washings were added to the crock. When all the product had been transferred from the flask to the crock, the contents were stirred vigorously for 25-30 minutes. The reaction mixture was cooled in the refrigerator overnight. The product was filtered and washed with ice-cold water. The crude product was allowed to air dry and then recrystallized from ethano1. The yield of o-bromobenzaldehyde diacetate was 72-78 gm; (43-47\%), M.P. $90-91^{\circ} \mathrm{C}$.

o-Bromobenzaldehyde

$28.7 \mathrm{~g}(0.10 \mathrm{~mole})$ of $\mathrm{o}$-bromobenzaldehyde diacetate was refluxed with $50 \mathrm{ml}$ of concentrated hydrochloric acid and 150-200 ml water 
for approximately one hour. The o-bromobenzaldehyde was steam distilled directly from the hydrolysis mixture. The distillate was separated from the water, dried and then placed in the refrigerator. The o-bromobenzaldehyde settled out as a solid. Yield, $22.2 \mathrm{~g}$ (78\%). The o-bromobenzaldehyde was distilled under vacuum before being used. B.P. $118-119^{\circ} \mathrm{C} / 12 \mathrm{~mm}$.

\section{o-Iodotoluene (44)}

This compound was prepared by the method of Morgan and Coulson (45). A solution of $32.1 \mathrm{~g}(0.3 \mathrm{~mole})$ o-toluidine in a solution of $60 \mathrm{~g}$ of concentrated sulfuric acid and $450 \mathrm{ml}$ of water was diazotized at a temperature below $5^{\circ}$ by the addition of a solution of $21 \mathrm{~g}$ of sodium nitrite in $60 \mathrm{ml}$ of water. The resulting solution of the diazonium salt was filtered, and the filtrate was added to a solution of $60 \mathrm{~g}$ of potassium iodide in $60 \mathrm{ml}$ of water. After standing one hour at room temperature, the mixture was warmed until evolution of nitrogen ceased. Sufficient solid sodium bisulfite was added to discharge the free iodine. The separated oil was removed by extraction with ether, and the ethereal solution was distilled after being washed with $10 \%$ aqueous sodium hydroxide and dried over calcium chloride. After removal of the ether by distillation, the residual oil was distilled from solid potassium hydroxide to give $35 \mathrm{~g}(54.0 \%)$ of the lodocompound. B.P. $85-86^{\circ} \mathrm{C} / 12 \mathrm{~mm}$. 
o-Iodobenzaldehyde $(45,46)$

This compound was prepared according to the method described in organic reactions, Vo1. VIII, 210, 1954. A gent1y refluxing mixture of $87.2 \mathrm{~g}(0.4 \mathrm{~mole})$ of 0 -iodotoluene, $240 \mathrm{ml}$ of carbon tetrachloride, and $80 \mathrm{ml}$ water containing a little iodine, irradiated by three 75-watt lamps, was treated during two hours with a solution of $48 \mathrm{~g}$ of bromine in $120 \mathrm{ml}$ of carbon tetrachloride. After heating at reflux temperature for one additional hour, the solvents were removed as completely as possible by distilling from a steam bath. The organic layer was separated from the water, diluted with $60 \mathrm{ml}$ of chloroform, and then heated in a boiling-water bath under reduced pressure until all the chloroform and water were removed. After cooling, a solution of $80 \mathrm{~g}$ of hexamine in $800 \mathrm{ml}$ of chloroform was added to the residue and the mixture was allowed to stand overnight. The separated hexaminium salt was collected on a Buchner funnel, washed with a little chloroform, and dried in air for about one hour. The salt was then dissolved in a mixture of $120 \mathrm{ml}$ of glacial acetic acid and $120 \mathrm{ml}$ of water and heated at reflux temperature for one and one half hours. The mixture was cooled, diluted with water, and extracted several times with ether. The ethereal extracts were washed with sodium carbonate solution, then with water, and finally dried. Distillation under reduced pressure provided $25 \mathrm{~g}(27 \%)$ of a yellow oil which completely solidified to a light yellow solid, M.P. $30^{\circ} \mathrm{C}$ upon standing. 
$\gamma$-o-Chlorophenylparaconic Acid

This compound was prepared by the method of Fuson (7). $12 \mathrm{~g}$ $(0.12$ mole) of succinic anhydride and $10 \mathrm{~g}$ ( 0.12 mole) of freshly fused sodium acetate were mixed in a mortar and the mixture dried at $100^{\circ} \mathrm{C}$ in the oven for half an hour. The mixture was placed in a fläsk, and $17.1 \mathrm{~g}(0.12 \mathrm{~mole})$ of o-chlorobenzaldehyde was added at one time. The flask was fitted with an air condenser, and a calcium chloride drying tube. The flask was immersed in a wax bath at $140^{\circ} \mathrm{C}$ and kept at this temperature until the mixture began to turn dark and a moderate evolution of carbon dioxide was observed. The bath was allowed to $\operatorname{cool}$ to $120^{\circ} \mathrm{C}$ and was kept at this temperature for three hours. The crude product was steam distilled and $1.6 \mathrm{~g}$ of 0 -chlorobenzaldehyde was recovered. The liquid residue from the steam distillation was filtered while hot, to remove a tarry material. The filtrate was cooled in an ice bath and then acidified with concentrated hydrochloric acid. A white solid separated which was filtered with suction. A second crop of crystals was obtained by the evaporation of the mother liquid to one fourth of the original volume. The combined products were recrystallized from water-ethanol (10\%) yield, $21.5 \mathrm{~g}(81.2 \%)$, M.P. $144-146^{\circ} \mathrm{C}$. Infrared spectrum showed that the material gave adsorptions consistent with the structure of $\gamma$-o-chlorophenylparaconic acid, and noted as follows: $3.30-3.81 \mu, 5.66 \mu, 5.78 \mu, 6.81 \mu$, $8.43 \underline{\mu}$, and $13.18 \mu$ 스. H, 3.77; C1, 14.73. Found: C, 54.46; H, 3.77; C1, 14.74. 
$\gamma$-o-Bromophenylparaconic Acid

The $\gamma$-o-bromophenylparaconic acid was prepared from $12 \mathrm{~g}$ $(0.12 \mathrm{~mole})$ of succinic anhydride, $10 \mathrm{~g}(0.12 \mathrm{~mole})$ of fresh $1 \mathrm{y}$ fused sodium acetate and $21.4 \mathrm{~g}(0.11 \mathrm{~mole})$ of o-bromobenzaldehyde. The procedure followed was identical with that used to prepare $\gamma$-o-chlorophenylparaconic acid. Yield, $24.6 \mathrm{~g}(75.3 \%)$. M.P. $155-156^{\circ} \mathrm{C}$. It showed infrared adsorptions as follows: $3.30-4.00 \mu, 5.71 \mu, 5.81 \mu$, $6.81 \mu$, $8.50 \underline{\mu}$, and $13.2 \underline{\mu}$. Ana1. Calculated for $\mathrm{C}_{11} \mathrm{H}_{9} \mathrm{O}_{4} \mathrm{Br}$ : C, 46.34; $\mathrm{H}, 3.18 ; \mathrm{Br}, 28.03$. Found: C, 46.00; H, 3.25; $\mathrm{Br}, 28.49$.

\section{$\gamma$-o-Fluorophenylparaconic Acid}

The $\gamma$-o-fluorophenylparaconic acid was prepared from $8.1 \mathrm{~g}$ $(0.081$ mole $)$ of succinic anhydride, $7.0 \mathrm{~g}(0.085 \mathrm{~mole})$ of freshly fused sodium acetate and $10 \mathrm{~g}(0.081 \mathrm{~mole})$ of o-fluorobenzaldehyde. The method followed was essentially the same as that described for the preparation of $\gamma$-o-chlorophenylparaconic acid, with the following modification. When the reaction began as evidenced by the vigorous evolution of carbon dioxide, the reaction vessel was removed from the $140^{\circ} \mathrm{C}$ oil bath and when the temperature dropped to $120^{\circ} \mathrm{C}$ was reimmersed in the oil bath. The reaction mixture was heated at this temperature for three additional hours. Yield, $11.4 \mathrm{~g}(62.0 \%)$. M.P. $156-158^{\circ} \mathrm{C}$. It showed infrared absorptions at: $3.11-3.85 \underline{u}, 5.71 \mu, 5.81 \mu$, $6.81 \underline{\mu}, 8.41 \underline{\mu}$, and $13.81 \underline{\mu}$. Ana1. Calculated for $\mathrm{C}_{11} \mathrm{H}_{9} \mathrm{O}_{4} \mathrm{~F}$ : C, 58.93; H, 4.05; F, 8.47. Found: C, 58.98; H, 4.09; F, 8.24. 
$\gamma$-o-Iodophenylparaconic Acid

The procedure followed for the preparation of $\gamma$-o-o-iodopheny1paraconic acid was essentially that used to prepare $\gamma-\underline{0}$-chloropheny1paraconic acid, with the same modification as noted in the preparation of $\gamma$-o-fluorophenylparaconic acid. Also the heating period was for five hours. The quantities of materials used were $5.4 \mathrm{~g}$ (0.054 mole) of succinic anhydride, $4.9 \mathrm{~g}(0.059 \mathrm{~mole})$ of freshly fused sodium acetate, and $12.5 \mathrm{~g}(0.054 \mathrm{~mole})$ of o-iodobenzaldehyde. Yleld, $13.05 \mathrm{~g}$ $(74.4 \%)$. M.P. $150-151^{\circ} \mathrm{C}$. It showed infrared absorptions at $3.16-3.71 \underline{\mu}$, $5.61 \mu, 5.79 \mu, 8.52 \mu, 10.00 \mu$, and $13.21 \mu$. Anal. Calculated for $\mathrm{C}_{11} \mathrm{H}_{9} \mathrm{O}_{4} \mathrm{I}: \mathrm{C}, 39.78 ; \mathrm{H}, 2.73 ; \mathrm{I}, 38.21$. Found: C, 40.04; H, 2.77; I, 37.99 . $\gamma$-o-Nitrophenylparaconic Acid

The $\gamma$-o-nitrophenylparaconic acid was prepared from $10.0 \mathrm{~g}$ $(0.1 \mathrm{~mole})$ of succinic anhydride, $9.0 \mathrm{~g}$ ( $0.11 \mathrm{~mole})$ of freshly fused sodium acetate and $16.6 \mathrm{~g}(0.1 \mathrm{~mole})$ of $\gamma$-o-nitrophenylparaconic acid. The procedure followed was essentially that used to prepare $\gamma$-o-chlorophenylparaconic acid with the same modification as noted in the preparation of $\gamma$-o-fluorophenylparaconic acid. Yield, $10.6 \mathrm{~g}$ (38.3\%). M.P. $163-165^{\circ} \mathrm{C}$. It gave infrared absorptions at $3.21-3.92 \underline{\mu}, 5.62 \underline{\text { }}$, $5.88 \underline{\mu}, 6.6 \underline{\mu}, 7.49 \underline{\mu}, 9.92 \underline{\mu}, 12.76 \underline{\mu}$ and 13.31 ㅆ․ Ana1. Calculated for $\mathrm{C}_{11} \mathrm{H}_{9} \mathrm{O}_{6} \mathrm{~N}: \quad \mathrm{C}, 52.60 ; \mathrm{H}, 3.61 ; \mathrm{N}, 5.58$. Found: C, 52.41; $\mathrm{H}, 3.50$; $\mathrm{N}, 5.67$. 
Determination of the molecular weight of $\gamma$-o-Halophenylparaconic Acid.

The $\gamma$-o-halophenylparaconic acid was dissolved in $2 \mathrm{~m} 1$ of ethanol and $25 \mathrm{ml}$ of deionized water, and titrated with sodium hydroxide solution, using phenolphthalein as the indicator. The results are shown in the following table.

TABLE IX

Determination of Molecular Weight

$\begin{array}{llllll}\text { Acid } & \begin{array}{c}\text { Sample } \\ \text { Weight }\end{array} & \begin{array}{l}\text { NaOH used } \\ (0.1126 \mathrm{~N})\end{array} & \begin{array}{l}\text { Equiv. } \\ \text { Weight }\end{array} & \begin{array}{l}\text { Expected } \\ \text { Mo1. Wt. }\end{array} & \begin{array}{l}\text { Found } \\ \text { Mo1. Wt. }\end{array} \\ -\mathrm{F} & 0.4761 \mathrm{~g} & 37.68 \mathrm{ml} & 112.22 & 224 & 224 \\ -\mathrm{Cl} & 0.3358 \mathrm{~g} & 24.72 \mathrm{ml} & 120.63 & 240 & 241 \\ -\mathrm{Br} & 0.4621 \mathrm{~g} & 28.77 \mathrm{ml} & 142.61 & 285 & 286 \\ -\mathrm{I} & 0.3645 \mathrm{~g} & 19.39 \mathrm{ml} & 166.91 & 332 & 333 \\ -\mathrm{NO}_{2} & 0.3973 \mathrm{~g} & 27.93 \mathrm{ml} & 126.31 & 251 & 252\end{array}$

Decarboxylation of $\gamma$-o-Chlorophenylparaconic Acid

A mixture of $1.0 \mathrm{~g} \gamma$-o-chlorophenylparaconic acid and $5 \mathrm{mg}$ of potassium hydrogen sulfate in a $10 \mathrm{ml}$ flask was immersed in an oil bath (Dow Corning, 550 fluid) at $230^{\circ}$. A vigorous evolution of gas occured which gradually subsided, and after a period of seventy minutes there was no further evidence of decarboxylation. Distillation at reduced pressure with a rapid increase in temperature from $230^{\circ}$ to $305^{\circ} \mathrm{C}$ within ten minutes afforded a slightly yellow oil which solidified on standing. The crude material was dissolved in ether, and extracted repeatedly with saturated sodium bicarbonate solution unt1l the sodium bicarbonate 
solution gave no cloudiness upon acidification. The ether layer was then extracted with $5 \%$ potassium hydroxide. Treatment of the alkaline solution with concentrated hydrochloric acid gave the crude 5-chloro1-naphthol in $8.1 \%$ yield.

After acidification of the sodium bicarbonate solution, the crude $\gamma$-o-chloro-phenylisocrotonic acid precipitated. The solid was filtered with suction, washed with ice-cold water, and dried in a vacuum dessicator over calcium chloride. Yield, $0.58 \mathrm{~g}$ (71\%). Recrystallization from petroleum-ether (B.P. $60-90^{\circ} \mathrm{C}$ ) gave white crystals with a M.P. $84.5-86.5^{\circ} \mathrm{C}$. The compound showed infrared absorptions at: 3.03-3.67 u, $5.92 \underline{u}, 6.34 \underline{u}, 8.29 \underline{u}, 10.44 \underline{u}$, and $13.39 \underline{u}$. Ana1. Calculated for $\mathrm{C}_{10} \mathrm{H}_{9} \mathrm{O}_{2} \mathrm{Cl}$ : C, 61.08; $\mathrm{H}, 4.61 ; \mathrm{Cl}, 18.03$. Found: C, $61.25 ; \mathrm{H}, 4.62 ; \mathrm{C} 1,18.02$.

\section{Decarboxylation of $\gamma$-o-Bromophenylparaconic Acid}

A mixture of $3 \mathrm{~g} \gamma$-o-bromophenylparaconic acid and $15 \mathrm{mg}$ of potassium hydrogen sulfate was heated in an oil bath at $225^{\circ} \mathrm{C}$ for one hour and fifty minutes. Distillation under vacuum (c.a. $5 \mathrm{~mm}$ ) at $225^{\circ} \mathrm{C}$ afforded a light yellow oil which solidified on standing. The crude material was dissolved in ether and extracted repeatedly with saturated sodium bicarbonate solution until the sodium bicarbonate solution gave no cloudiness upon acidification.

Extraction of the ethereal solution with $5 \%$ potassium hydroxide, followed by acidification yielded no naphthol derivative.

Acidification of the sodium bicarbonate solution precipitated the $\gamma$-o-bromophenylisocrotonic acid. The solid product was collected 
in a Buchner funnel, washed with ice-cold water and dried in a vacuum dessicator. Yield, $1.97 \mathrm{~g}(77.5 \%)$. Recrystallization from petroleumether (B.P. $60-90^{\circ} \mathrm{C}$ ) gave white crystals with a M.P. $101-103^{\circ} \mathrm{C}$. The compound showed infrared absorptions at: $3.34-3.88 \underline{\underline{u}}, 5.90 \underline{u}, 6.12 \underline{\text { u}}$, $8.31 \underline{u}, 10.36 \underline{u}$, and 13.56 u. Anal. Calculated for $\mathrm{C}_{10} \mathrm{H}_{9} \mathrm{O}_{2} \mathrm{Br}$ : C, 49.82; H, 3.76; $\mathrm{Br}, 33.15$. Found: C, 49.90; H, 3.77; Br, 33.16. Decarboxylation of $\gamma$-o-Fluorophenylparaconic Acid

A mixture of $3 \mathrm{~g} \gamma$-o-fluorophenylparaconic acid and $15 \mathrm{mg}$ of potassium hydrogen sulfate was heated in an oil bath in a distillation flask at $230^{\circ} \mathrm{C}$ for sixty-eight minutes. The decarboxylation mixture was processed in a manner analogous to that described in the decarboxylation of $\gamma$-o-bromophenylparaconic acid. Yield, $1.85 \mathrm{~g}(77 \%)$. M.P. $62-63^{\circ} \mathrm{C}$. It gave infrared absorptions at: $3.30-3.81 \underline{\mathrm{u}}, 5.91 \underline{\mathrm{u}}$, $6.33 \underline{u}, 6.73 \underline{u}, 8.14 \underline{u}, 10.25 \underline{u}$, and $13.43 \underline{u}$. Anal. Calculated for

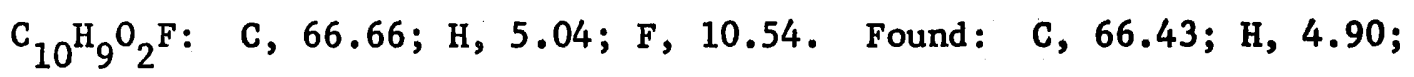
F, 10.39 .

\section{Decarboxylation of $\gamma$-o-Iodophenylparaconic Acid}

A mixture of $2.1 \mathrm{~g} \gamma$-o-o-iodophenylparaconic acid and $10 \mathrm{mg}$ of potassium hydrogen sulfate was heated in an oll bath in a distillation flask at $225^{\circ} \pm 3^{\circ} \mathrm{C}$ for sixty-five minutes. The decarboxylation mixture was processed in a manner analogous to that described in the decarboxylation of -o-bromophenylparaconic acid. Yield, $1.36 \mathrm{~g}$ (74\%). M.P. $120-122^{\circ} \mathrm{C}$. It gave infrared absorptions at: $3.28-3.86 \underline{u}, 5.87 \underline{u}$, $8.3 \underline{u}, 10.32 \underline{u}$, and $13.52 \underline{u}$. Anal. Calculated for $\mathrm{C}_{10} \mathrm{H}_{9} \mathrm{O}_{2} \mathrm{I}$ : C, 41.69; 
H, 3.15; I, 44.05. Found: C, 41.79; H, 3.37; I, 44.15.

Determination of molecular weight of $\gamma$-o-Halophenylisocrotonic Acid

The $\gamma$-o-halophenylisocrotonic acid was dissolved in $2 \mathrm{~m} 1$ of ethanol and $25 \mathrm{ml}$ of delonized water, and titrated with sodium hydroxide solution, using phenolphthalein as the indicator.

\section{TABLE $\mathrm{X}$}

Determination of Molecular Weight

\begin{tabular}{lcccc} 
Acid & $\begin{array}{l}\text { Sample } \\
\text { Weight }\end{array}$ & $\begin{array}{l}\text { NaOH used } \\
(0.0981 \mathrm{~N})\end{array}$ & $\begin{array}{l}\text { Expected } \\
\text { Mo1.Wt. }\end{array}$ & $\begin{array}{l}\text { Found } \\
\text { Mo1. Wt. }\end{array}$ \\
\cline { 2 - 3 } & $0.4431 \mathrm{~g}$ & $24.99 \mathrm{ml}$ & 180 & 180 \\
$\mathrm{C1}$ & $0.3925 \mathrm{~g}$ & $20.37 \mathrm{ml}$ & 196 & 197 \\
$\mathrm{Br}$ & $0.3836 \mathrm{~g}$ & $16.14 \mathrm{ml}$ & 241 & 242 \\
$\mathrm{I}$ & $0.3965 \mathrm{~g}$ & $11.53 \mathrm{ml}$ & 288 & 289 \\
& $0.6473 \mathrm{~g}$ & $18.67 \mathrm{ml}$ & 288 & 288 \\
& & & &
\end{tabular}

Cyclization of $\gamma$-o-Chlorophenylisocrotonic Acid

In a $250 \mathrm{ml}$ round bottom flask was placed $1.4 \mathrm{~g}$ of $\gamma$-o-chlorophenylisocrotonic acid, $0.60 \mathrm{~g}$ of anhydrous sodium acetate and $12.7 \mathrm{ml}$ of acetic anhydride. The mixture was placed in an oil bath at $150^{\circ}$, irradiated with a U.V. light (Cenco Quartz Mercury arc U.V. region $2260 \AA$ ) and refluxed in an oil bath at $150^{\circ} \mathrm{C}$ for thirty-five minutes. After this period, $54 \mathrm{ml}$ of $5 \%$ sodium hydroxide was introduced, and the mixture was refluxed for an additional fifteen minutes. Due to the fact that the mixture was still acidic ( $\mathrm{pH} \sim 6), 21 \mathrm{ml}$ of $30 \%$ sodium 
hydroxide was added. The mixture was refluxed for three hours during which time a red oil separated. After the mixture was filtered and the red oil was removed, the yellow solution was acidified with concentrated hydrochloric acid. Slightly yellow silky-like needles separated. Yield, $0.81 \mathrm{~g}(62.2 \%)$. The product was recrystallized once from hot water and then from petroleum-ether (B.P. $60-90^{\circ} \mathrm{C}$ ). M.P. 131-132. It showed infrared absorptions at: 2.99-3.62 뜨,' $6.32 \underline{u}, 8.07 \underline{u}, 11.43 \underline{u}$, and 12.92 u. Anal. Calculated for $\mathrm{C}_{10^{\mathrm{H}}} \mathrm{H}^{\mathrm{OC} 1}$ : C, 67.24; H, 3.95; C1, 19.85. Found: C, 67.04; H, 4.02; C1, 19.65 .

\section{Cyclization of $\gamma$-o-Bromopheny1isocrotonic Acid}

A mixture of $1.0 \mathrm{~g}$ of $\gamma$-o-bromophenylisocrotonic acid, $0.34 \mathrm{~g}$ of anhydrous sodium acetate and $7.3 \mathrm{ml}$ of acetic anhydride in a $100 \mathrm{~m} 1$ flask was refluxed in an oil bath at $150^{\circ} \mathrm{C}$ for thirty minutes. During this time the reaction mixture was irradiated with U.V. Iight. Hydrolysis was accomplished using $3.1 \mathrm{ml}$ of $5 \%$ sodium hydroxide and $10 \mathrm{ml}$ of $30 \%$ sodium hydroxide. The work-up and isolation were the same as that described for the cyclization of $\gamma$-o-chlorophenylisocrotonic acid. Yield, $0.4 \mathrm{~g}(51.1 \%)$ M.P. $135.5-136^{\circ} \mathrm{C}$. It showed infrared absorptions at: $3.11-3.39 \underline{u}, 6.31 \underline{u}, 7.29-7.50 \underline{u}, 8.03 \underline{u}$, and $12.97 \underline{u}$. Anal. Calculated for $\mathrm{C}_{10} \mathrm{H}_{7} \mathrm{OBr}$ : C, 53.84; $\mathrm{H}, 3.16 ; \mathrm{Br}, 35.82$. Found: $\mathrm{C}, 53.61 ; \mathrm{H}, 3.25 ; \mathrm{Br}, 36.22$.

\section{Cyclization of $\gamma-0-$ Fluorophenylisocrotonic Acid}

A mixture of $2.43 \mathrm{~g}$ of $\gamma$-o-fluorophenylisocrotonic acid, $1.11 \mathrm{~g}$ anhydrous sodium acetate, and $23.6 \mathrm{ml}$ of acetic anhydride in a $250 \mathrm{ml}$ 
flask was refluxed in an oil bath at $150^{\circ} \mathrm{C}$ for thirty minutes. During this time the reaction mixture was ixradiated with U.V. 1ight. $100 \mathrm{~m} 1$ of $5 \%$ sodium hydroxide and $33 \mathrm{ml}$ of $30 \%$ sodium hydroxide were used in the hydrolysis. The work-up and isolation were identical as that described for the cyclization of $\gamma$-o- chlorophenylisocrotonic acid. Yield, $0.81 \mathrm{~g}(46.5 \%)$. M.P. $129.5-130.5^{\circ} \mathrm{C}$. It showed infrared absorptions at: $2.96-3.54 \underline{u}, 6.28 \underline{u}, 7.20 \underline{u}, 8.03 \underline{u}, 10.84 \underline{u}$, and 12.94 u. Anal. Calculated for $\mathrm{C}_{10} \mathrm{H}_{7} \mathrm{OF}$ : C, 74.07; H, 4.35; F, 11.72. Found: $\mathrm{C}, 73.80 ; \mathrm{H}, 4.30 ; \mathrm{F}, 11.69$.

\section{Cyclization of $\gamma$-o-Iodophenylisocrotonic Acid}

A $100 \mathrm{ml}$ flask containing $1.0 \mathrm{~g}$ of $\gamma$-o- - iodophenylisocrotonic acid, $0.28 \mathrm{~g}$ anhydrous sodium acetate, and $6 \mathrm{ml}$ acetic anhydride was refluxed in an oil bath at $150^{\circ} \mathrm{C}$ for thirty minutes. During this time the reaction mixture was irradiated with U.V. 1ight. $26 \mathrm{ml}$ of $5 \%$ sodium hydroxide and $8.5 \mathrm{ml}$ of $30 \%$ sodium hydroxide were employed for the hydrolysis. The work-up and isolation were the same as that described for the cyclization of $\gamma$-o-chlorophenylisocrotonic acid. Yield, $0.38 \mathrm{~g}(40.5 \%)$. M.P. $126-127^{\circ} \mathrm{C}$. It showed infrared absorptions at 2.98-3.34 u, $6.28 \underline{u}, 8.04 \underline{u}$, and $12.89 \underline{u}$. Anal. Calculated for $\mathrm{C}_{10} \mathrm{H}_{7} \mathrm{OI} ; \mathrm{C}, 44.47 ; \mathrm{H}, 2.61 ; \mathrm{I}, 46.99$. Found: C, 44.51; H, 2.80; I, 46.54. 


\section{SUMMARY}

The $\gamma$-o-halophenylparaconic acids have been prepared in good yield by the application of the Perkin condensation using the o-substituted-benzaldehydes and succinic anhydride. The $\gamma$-o-nitrophenylparaconic acid was also prepared.

Attempted synthesis of $\gamma-\underline{-o-b r o m o}$ and $\gamma$-o-chlorophenylisocrotonic acid under the same reaction conditions employed by Fittig and Jayne for the synthesis of $\gamma$, phenylparaconic acid, resulted in a tarry material with no expected $\gamma$-o-halophenylisocrotonic acid. Decarboxylation of $\gamma$-o-substituted-phenylparaconic acids was carried out at various temperatures, utilizing different solvents, and catalysts. Acid-catalyzed decarboxylation of $\gamma$-o-halophenylparaconic acid was found to be facilitated by potassium hydrogen sulfate. The time required for acid-catalyzed decarboxylation was reduced to one-half of that necessary for thermal decarboxylation. The yield of the $\gamma$-o-halophenylisocrotonic acids were: $C 1,71.0 \%$; $\mathrm{Br}, 77.0 \% ; \mathrm{I}, 74.0 \%$.

Infrared absorptions indicated that the $\gamma$-o-halophenylisocrotonic acid existed in the trans form.

The attempted cyclization of the trans $\gamma$-o-halophenylisocrotonic acid by refluxing with sodium acetate and acetic anhydride, gave negative results. Isomerization of the trans acid to the cis acid by ultra-violet irradiation, followed by refluxing with sodium acetate and acetic anhydride, afforded the cyclized product, 1-acetoxy-5halonaphthol. The latter compound was easily hydrolyzed to the 5-halo-1-naphthol in good yield. 


\section{BIBLOGRAPHY}

(1) Perkin, W. H., J. Chem. Soc., 21, 53, 181 (1868).

(2) Fittig and Jayne, Ann., 216, 100 (1883).

(3) Perkin, W. H., J. Chem. Soc., 31, 388 (1877).

(4) Adams, A., Organic Reactions, Vo1. 1, 212 (1942).

(5) Erdmann and Kirchhoff, Ann., 247, 366 (1888).

(6) Erdmann and Schwechter, Ann., 247, 65 (1888).

(7) Fuson, R. C., J. Am. Chem. Soc., 46, 2779-88 (1924).

(8) Fuson, R. C., J. Am. Chem. Soc., 47, 516-8 (1925).

(9) Angeletti, A., Gazz. Chim. ital, 59, 851-8 (1929).

(10) Schenck, Friedrich, J. Prakt. Chem., 141, 299 (1934).

(11) Miller, R. E. and Nord, F. F., J. Org. Chem., 12, 728 (1951).

(12) Anteunis, G. M., Bu11. Soc. Chim. Be1g., 69, 356 (1960).

(13) Oda, Kawabata, Tanimoto, Tetrahedron Letters, 1964, 25-26, 1653.

(14) Price, C. C., J. Am. Chem. Soc., 84, 489 (1962).

(15) Erdmann and Kirchhoff, Ann., 247, 372 (1888).

(16) Fieser, L. F. and Brown, H., J, Am. Chem. Soc., 71, 3615 (1949).

(17) Beech and Legg, J. Chem. Soc., 1887-9 (1949).

(18) Luric, A. P., J. Am. Chem. Soc., 83, 5015 (1961).

(19) Franzen, J. S. and Buckley, B. S., J. Org. Chem., 24, 992 (1959).

(20) Vorozhtsov and Lisitsyn, Zhur Obshchei Khim, 30, 2816 (1960).

(21) E1-Abbady, Doss, Moussa and Nosseir, J. Org. Chem., 26, 4871 (1961).

(22) Borsche, Kettner, Ann., 526, 1 (1936).

(23) Borsche, and Leditschke, Ann., 108 (1937).

(24) Guareschi, Ann., 222, 290 (1884). 
(25) U11mann and Consonno, Ber., 35, 2883 (1902).

(26) Hill, P. and Short, W. F., J. Chem. Soc., 1619-22 (1937).

(27) Adcock, W. and Dewar, M. J. S., J. Am. Chem. Soc., 89, 386 (1966).

(28) Martin, E. I., J. Am. Chem. Soc., 58, 1440 (1936).

(29) Fieser, L. F. and Selizman, A. M., J. Am. Chem. Soc., 60, 170 (1938).

(30) Scholl, R. and Seer, C., Monatsh, 42, 405-9 (1922).

(31) Traft, R. W., J. Am. Chem. Soc., 74, 3120-26 (1952).

(32) Richter, von Victor, "Organic Reaction," Blakiston's Son \& Co., Philadelphia, Penn., Vó1. 1, 612.

(33) Fittig, Ber., 16, 373 (1883).

(34) Linstead, R. P., J. Chem. Soc., 115 (1941).

(35) Linstead, R. P., J. Chem. Soc., 580 (1933).

(36) Johnson and Petersen, J. Am. Chem. Soc., 69, 74 (1947).

(37) Johnson and Hunt, I. Am. Chem. Soc., 72, 935 (1950).

(38) Braun and Munch, Ann., 465, 52 (1928).

(39) Baddar, E1-Assal and Baghos, J. Chem. Soc., 1715 (1955).

(40) Baddar, Lanson, S., El-Assal and Baghos, J. Chem. Soc., 987 (1958).

(41) Borsche, Kettner, Gillis, Kuhn and Mantenffe1, Ann., 526, 1 (1936).

(42) Johnson and Goldman, J. Am. Chem. Soc., 66, 1030 (1944).

(43) Tsang, Wood and Johnson, Organic Synthesis, Vo1. III, 641 (1955).

(44) Shirley, A. D., "Preparation or Organic Intermediates," John Wiley \& Son, Inc., p. 185 (1951).

(45) Anet, Hughes, Marmion and Ritchie, Australian J. Sci. Research, $3 A, 333$ (1950).

(46) Adams, et a1, Organic Reactions, Vo1. III, 210-11 (1954). 